\title{
A Operação Cesárea no Brasil. Incidência, Tendências, Causas, Conseqüências e Propostas de Ação
}

* Professor Titular de Obstetrf cia, da Faculdade de Ciencias Médicas da Universidade Estadual de Campinas.

* Professor Assistente do De partamento de Tocoginecologia da Faculdade de Ciencias Médicas da Universidade Estadual de Campinas.

\author{
Antbal Faúndes \\ Jose Guilherme Cecatti
}

Os autores fazem uma análise sobre a situaçâo da operação cesárea no Brasil, que atingiu, na última década, ntveis de incidência extremamente elevados, superiores aos de qualquer outro pals. A partir dos dados dispontveis a ntvel nacional sobre a incidência de cesáreas ao longo dos anos, tenta-se caracterizar esta tendência e estabelecer suas diferenças sócio-econômicas e regionais, que mostram uma incidência mais alta para os individuos e regiōes mais favorecidos economicamente. Consideram-se, também, os fatores que influenciam esta alta incidência, incluindo os fatores sócio-culturais, de organização da atenção obstétrica e fatores institucionais e legais. Enfatiza-se a esterilização cirúrgica que, sendo proibida no pals, é realizada disfarçadamente através de uma indicação inadequada de cesárea. São analisadas, ainda, as conseqüencias sobre a morbidade e mortalidade materna e perinatal, seus efeitos sobre a fecundidade da população e dos gastos extras para os cofres públicos decorrentes desta situação. Finalmente, propõem-se uma série de intervençōes e mudanças que seriam necessárias a diversos niveis para reverter esta indesejável tendência de aumento da incidência de operaçōes cesáreas.

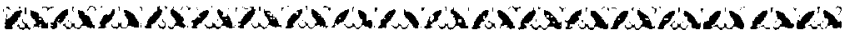

\section{TAXAS, TENDÊNCIAS E DIFERENÇAS SÓCIO- -ECONOMICAS E REGIONAIS}

O aumento na incidência de cesárea é um fenômeno comum a quase todos os países do mundo. Contudo, nāo sabemos de nenhum outro país onde a curva de aumento seja tão acentuada, nem as taxas tenham alcançado níveis tão altos, como no Brasil.

Há poucos dados estatísticos que permitam um seguimento adequado da tendência do índice de cesáreas. Os melhores sāo os fornecidos pelo Inamps, que paga cerca de $75 \%$ de todos os partos ocorridos no 
país. Os dados do Inamps publicados referem-se ao perfodo de 1970 a 1980 (Granado Neiva, 1982), e indicam um aumento do índice de cesáreas de 14,6\% em 1970 para $31 \%$ em 1980 (Tabela I).

\section{TABELA I}

Índices de Cesárea em Hospitais do Inamps. Brasil 1970 a 1980

\begin{tabular}{lrrr}
\hline & & & \\
Ano & Total Partos & Nám.Cesárea & $\%$ \\
\hline 1970 & 602.108 & 88.115 & 14,6 \\
1971 & 700.682 & 110.517 & 15,8 \\
1972 & 766.707 & 131.150 & 17,1 \\
1973 & 766.069 & 148.154 & 18,6 \\
1974 & 874.665 & 177.050 & 20,2 \\
1975 & 1.021 .904 & 235.898 & 23,1 \\
1976 & 1.211 .159 & 306.164 & 25,3 \\
1977 & 1.376 .307 & 354.869 & 25,8 \\
1978 & 1.379 .230 & 378.586 & 27,4 \\
1979 & 1.490 .860 & 446.185 & 29,9 \\
1980 & 1.591 .716 & 493.436 & 31,0 \\
& & & \\
\hline
\end{tabular}

Fonte: Granado-Neiva, 1982.

A Pesquisa Nacional por Amostra de Domicilios (PNAD), realizada em 1981 pelo Instituto Brasileiro de Geografia e Estatística (IBGE), obteve uma taxa de cesáreas para o Brasil de $30,9 \%$, um valor praticamente igual ao do Inamps em 1980, sendo que o IBGE entrevistou uma amostra representativa da população geral (IBGE, 1982). Esta pesquisa também revelou que, em todas as regiōes do Brasil, a incidência de cesáreas era tanto maior quanto maior o poder aquisitivo da mulher grávida, com base no salário familiar mensal (Tabela II).

Este achado confirma o resultado de diversos estudos menores que apontam que, já há muito tempo, $\mathrm{a}$ incidência é maior entre as pacientes privadas e menor entre as que recebem atendimento gratuito e que não têm seguro (Mello, 1969 - Tabela III). A sequeência mais comum de uma incidência mais baixa para uma mais alta é: indigência, seguro do Inamps, seguro particular e pagamento direto (Janowitz, 1982; Janowitz, 1985 e Rocha e cols., 1986).

Cadernos de Saúde Pública, RJ, 7 (2): 150-173, abr/jun, 1991 


\section{TABELA II}

Índices de Cesárea em Diversas Regiōes Brasileiras, por Renda Familiar Mensal

\begin{tabular}{lllllll}
\hline & \multicolumn{5}{c}{ Regiöes } \\
\cline { 2 - 6 } $\begin{array}{l}\text { Renda } \\
\text { Familiar } \\
\text { (salắrios } \\
\text { mfnimos) }\end{array}$ & Norte & Nordeste & Sudeste & Sul & C. Oeste & Brasil \\
\hline & & & & & & \\
\hline 1 & 26,7 & 12,3 & 20,7 & 21,6 & 21,9 & 16,7 \\
$1-2$ & 21,2 & 14,2 & 27,3 & 23,3 & 28,5 & 22,2 \\
$2-3$ & 26,1 & 22,9 & 30,8 & 22,8 & 34,9 & 27,6 \\
$3-5$ & 23,8 & 27,3 & 41,9 & 26,4 & 42,5 & 36,3 \\
$5-10$ & 48,6 & 38,0 & 48,9 & 40,7 & 50,4 & 45,9 \\
$<10$ & 43,2 & 54,0 & 61,5 & 43,8 & 60,2 & 57,6 \\
\hline Total & 28,4 & 20,0 & 37,6 & 27,0 & 37,4 & 30,9 \\
\hline
\end{tabular}

Fonte: IBGE, 1982.

\section{TABELA III}

Índices de Cesárea em Diversos Hospitais, por Tipo de Pagamento. Rio de Janeiro, 1969

\begin{tabular}{lcc}
\hline Hospital & $\begin{array}{c}\text { Pacientes sem } \\
\text { Seguro Social } \\
\%\end{array}$ & $\begin{array}{c}\text { Pacientes } \\
\text { do Inamps } \\
\%\end{array}$ \\
\hline Mãe Pobre & 7,0 & 15,2 \\
S. Franc. de Assis & 8,5 & 12,4 \\
Pró-Matre & 11,7 & 31,4 \\
Santa Casa & 13,7 & 24,4 \\
Clara Basbaum & 15,7 & 22,2 \\
\hline Total & 10,9 & 19,5 \\
\hline
\end{tabular}

Fonte: Mello, 1969.

Também podem ser observadas grandes variaçōes, quando analisamos as taxas de cesáreas por estado. $O$ estudo do IBGE de 1981 mostra uma grande diferença entre São Paulo, o mais rico, com $43,8 \%$, e os estados mais pobres como o Ceará $(17,7 \%)$ e Pernambuco (17,9\% - Tabela IV). A mesma tabela mostra que, enquanto os dois estados mais ricos (São Paulo 
e Rio de Janeiro) tinham taxas de cesárea mais altas para a população em geral do que para o Inamps, ocorria o oposto nos estados mais pobres como Ceará e Pernambuco. Uma explicação possível é que, enquanto em Sāo Paulo e Rio de Janeiro a população não-coberta pelo Inamps consistia, principalmente, de pacientes particulares das classes sociais mais ricas, nos estados do Nordeste, com altos níveis de desemprego, aquelas pessoas sem seguro do Inamps pertenciam às classes mais pobres da população. Assim, os ricos em São Paulo e Rio empurraram para cima as taxas de cesárea da população em geral e, no Ceará e Pernambuco, os indigentes trouxeram essas taxas para baixo, em comparação com as taxas do Inamps.

\section{TABELA IV}

Comparação dos Índices de Cesárea Entre os Dados do Inamps e do PNAD em Estados Selecionados (1980)

\begin{tabular}{lccc}
\hline & \multicolumn{2}{c}{ Índices de Cesárea } & \\
\cline { 2 - 3 } Estado & PNAD & Inamps & Diferença \\
\hline São Paulo & 43,7 & 38,6 & $+5,1$ \\
Rio de Janeiro & 39,2 & 31,4 & $+7,8$ \\
Goiás & 36,0 & 36,4 & $-0,7$ \\
Distrito Federal & 32,6 & 32,0 & $+0,6$ \\
Paraná & 32,4 & 31,9 & $+0,5$ \\
Rio Gde. Sul & 24,7 & 24,6 & $+0,1$ \\
Minas Gerais & 24,7 & 27,7 & $-3,0$ \\
Bahia & 19,7 & 19,5 & $+0,2$ \\
Pernambuco & 17,8 & 24,7 & $-6,9$ \\
Ceará & 17,6 & 20,8 & $-3,2$ \\
\hline Brasil & 30,9 & 31,0 & $-0,1$ \\
\hline
\end{tabular}

Fontes: IBGE, 1982 e Granado-Neiva, 1982.

Outro achado que requer maior explicação é que, enquanto nos estados menos desenvolvidos os índices mais elevados sāo para a capital, ocorre o oposto em Sāo Paulo. A PNAD de 1981 permite-nos comparar, por exemplo, o estado de Pernambuco com o de São Paulo, incluindo na análise apenas os partos hospitalares. Recife, capital de Pernambuco, teve uma taxa de cesáreas de $28,6 \%$, comparada com apenas $11,7 \%$ no resto do estado, enquanto que a região metropolitana de São Paulo teve uma taxa menor $(41,4 \%)$ comparada com o restante do estado $(46,7 \%$ - Tab.V).

Cadernos de Saúde Pública, RJ, 7 (2): 150-173, abr/jun, 1991 
Índices de Cesárea na Capital e Interior do Estado. São Paulo e Pernambuco, 1981

\begin{tabular}{|c|c|c|c|c|}
\hline \multirow[b]{2}{*}{ Estado } & \multicolumn{3}{|c|}{ Indices de Cesárea $(\%)$} & \multirow[b]{2}{*}{$x$} \\
\hline & Capital & Interior & Estado & \\
\hline São Paulo & 41,2 & 46,7 & 43,8 & 621.803 \\
\hline Pernambuco & 28,6 & 11,7 & 17,9 & 153.158 \\
\hline
\end{tabular}

Fonte: IBGE, 1982.

Este último achado foi confirmado, para o ano de 1987, pela Avaliação do Programa de Assistência Integral à Saúde da Mulher (PAISM) do Estado de São Paulo (Hardy e cols., 1988). Este estudo, com entrevistas domiciliares feitas com mais de $2.000 \mathrm{mu}-$ lheres de baixa renda na região metropolitana de São Paulo e mais de 1.700 no interior do estado, constatou uma taxa de $43,9 \%$ na capital e uma taxa mais elevada, de $52,5 \%$, no interior.

Uma possível explicaçāo para isto é que as facilidades necessárias para a realização de uma cesárea são encontradas com mais facilidade em Recife do que no interior de Pernambuco, enquanto que o interior de São Paulo é tão rico em recursos quanto a capital e, provavelmente, conta com obstetras menos treinados e com menor controle social da prática médica.

\section{FATORES QUE INFLUENCIAM A ALTA INCIDÊNCIA DE CESÁREAS}

A atual incidência excessivamente alta de cesáreas no Brasil não pode ser explicada apenas como um esforço para melhorar os resultados perinatais. $\mathrm{Na}$ verdade, como já foi demonstrado, as taxas são menores entre os pobres, possuidores dos índices mais altos de patologias obstétricas, distócias e outras complicações da gravidez e do parto.

$\mathrm{Na}$ ausência de dados confiáveis, fica mais difficil definir as razöes do aumento da incidência para o Brasil do que para os Estados Unidos e países da Europa. Várias hipóteses, baseadas principalmente em evidências indiretas, podem ser levantadas para explicar a preferência pela cesárea que existe atualmente, tanto entre as mulheres como entre os médicos que fazem os seus partos. Sem dúvida, ambos são influenciados por vários fatores sócio-culturais, institucionais e legais que serão discutidos a seguir. 


\section{Fatores sócio-culturais}

Desconhecemos qualquer estudo brasileiro publicado que vise avaliar a influência dos fatores sócio-culturais sobre a incidência de cesáreas. A discussão que se segue baseia-se na opinião coletiva de um grupo restrito de obstetras e outros especialistas brasileiros que se reuniram para rever o problema do aumento da incidência de cesáreas no país, incluindo os possíveis fatores determinantes (Unicamp, 1982).

As razões por que as mulheres preferem a cesárea ao parto vaginal seriam de dois tipos. Um é o medo da dor durante o trabalho de parto e o parto. A idéia é que uma cesárea eletiva, decidida com antecedência para dia e hora marcados, permitirá à mulher um parto sem qualquer dor, desde que receba também fortes analgésicos depois da cirurgia.

$\mathrm{O}$ outro é o conceito de que a cesárea permite à mulher manter intactas a anatomia e fisiologia da vagina e do períneo, enquanto que o parto vaginal produz perda acentuada da funçấo do coito normal. Esta interpretação um tanto mecânica da fisiologia da relação sexual tem sido encorajada até por famosos e distinguidos professores de obstetrícia, que transmitem estas idéias aos seus alunos, a ponto de ter se tomado um conceito prevalente entre médicos e pacientes.

Também, o inconveniente estético da cicatriz abdominal após uma cesárea tem sido evitado pelo uso quase universal da incisão de Pfannestiel, que deixa a cicatriz coberta pelo limite superior dos pelos púbicos.

Outro fator cultural importante é o conceito popular de que o parto vaginal $\varepsilon$ mais arriscado para o feto do que uma cesárea. Assim, um mau resultado neonatal é muitas vezes atribuído ao fato do médico nāo se ter decidido por uma cesárea, ao invés de um parto vaginal. Se uma morte neonatal ocorre após uma cesárea, será considerado que ocorreu "apesar" da "sábia" decisão de se realizar uma cesárea, mas nunca associada ao tipo de parto. Por outro lado, se um recém-nascido morre depois de um parto com fórcipe, a morte será sempre atribuída ao uso de fórcipe e não às circunstâncias que levaram a esta indicação de extração fetal. Esta crença popular toma-se um fator importante na decisão do obstetra quanto ao tipo de parto.

\section{Organização da atenção obstétrica: conveniência e segurança do médico}

A preferência dos médicos pela cesariana pode ter várias origens. Contudo, atualmente, o que domina 
é a conveniência de uma intervenção programada, que não tomará mais que uma hora de seu tempo, ao contrário do parto vaginal que pode ocorrer a qualquer hora do dia ou da noite, fins de semana ou feriados, e que ocupará um período maior e imprevisível de seu tempo.

Também a incerteza quanto à possibilidade de hipóxia ou trauma fetal durante o trabalho de parto e parto nas mãos de profissionais que não têm um bom treinamento obstétrico, como é o caso da maioria dos partos no Brasil, pode ter uma influência importante na decisão de intervir.

A coincidência desses conceitos com o treinamento obstétrico incompleto e a conseqüente falta de segurança do médico em sua habilidade, explicam por que em muitos hospitais somente os trabalhos de parto mais fáceis e mais rápidos permitem-se evoluir para um parto vaginal, e por que uma distócia mínima, seja ela real ou imaginária, resulta automaticamente na decisão de se realizar uma cesárea.

A maneira como se pratica a assistência obstétrica no Brasil também contribui para esta situação. O cuidado pré-natal, em geral, não prepara a mulher grávida psicologicamente para o parto. $O$ medo e insegurança que toda mulher grávida sente são mais estimulados do que prevenidos no pré-natal que ela recebe e no contexto social em que ela passa a sua gravidez. Portanto, o medo da dor no parto é exacerbado com as primeiras contraçōes uterinas, requerendo um apoio psicológico para a mãe. Isto praticamente inexiste hoje no Brasil, uma vez que no atual sistema de saúde a figura da parteira quase desapareceu.

A falta de parteiras também contribui para a perda do conceito e da prática do trabalho em equipe no cuidado obstétrico. Com a exceção de alguns poucos serviços públicos e hospitais universitários que mantêm uma equipe de residentes, internos e pessoal clínico, a maior parte da assistência obstétrica está individualizada. Um médico cuida de várias grávidas, e cada mulher só aceitará aquele médico na atenção ao seu parto. Obviamente, cada médico tem a sua rotina profissional e particular. Ele tem seu consultório, visitas ao hospital, participação em conferências e congressos e sua vida familiar. Todas estas rotinas seräo abaladas por uma mulher em trabalho de parto, que precisa do médico ao seu lado para controlar a frequência cardfaca fetal e os outros parâmetros que indicam o decurso normal do parto. Para poder fomecer o cuidado necessário a nível individual, o médico terá de abandonar todas as outras atividades durante seis, doze ou mais horas seguidas. Talvez uma vez por semana, durante certo tempo, ele tenha disposição de fazê-lo, mas quando isso começa a atrapalhar a sua vida, a 
tentação de encurtar o processo com uma cesárea é grande demais. Como a atenção é pessoal, ninguém pode criar objeção ou discutir a indicação da intervenção. O hospital lucra com esta decisão e a família é poupada da tensão e da espera pelo resultado do parto.

Se a clientela de um médico cresce demais, então uma cesárea com dia e hora marcados fica ainda mais conveniente, especialmente se dois ou mais casos podem ser "resolvidos" juntos. Às mulheres é oferecida a conveniência de não experimentar sequer uma contração dolorosa, de decidir a data do parto e todos os detalhes práticos que podem ser providenciados, quando se sabe com antecedência o dia exato em que a criança irá nascer.

Entendemos que praticamente não possuímos dados objetivos que comprovem estas afirmativas. Não existe no Brasil qualquer estudo que determine a influência do fator do médico sobre a incidência de cesáreas. Contudo, existe uma recente publicação que mostra os resultados de um estudo feito nos Estados Unidos, onde foi constatado que o médico tem uma influência importate na taxa de cesarianas, perdendo apenas para a nuliparidade (Goyert e cols., 1989).

\section{Fatores institucionais e legais: esterilização cirúr- gica}

Visto que cerca de três quartos de todos os partos são financiados pelo Inamps, sua política de pagamento tem grande influência sobre a atual situação. $O$ fato do Inamps pagar diretamente aos médicos que atendem os partos é um fator que contribui para estimular as práticas descritas acima. Outro fator é que ele não paga pela analgesia peridural, meio mais difundido e eficaz de alívio da dor no Brasil, se o parto for vaginal. Paga somente se esta anestesia for utilizada para a realização de uma cesárea. Ou seja, se uma mulher dá prioridade a evitar a dor e pretende que seu parto seja pago pelo Inamps, ela não tem outra escolha senão uma cesárea. O maior risco para a mãe e o feto é ignorado ou contestado.

Até 1980 o Inamps pagava mais aos médicos por uma cesárea do que por um parto normal. Após verificar que a taxa de cesáreas havia dobrado em apenas $\operatorname{dez}$ anos, o Inamps mudou a sua política de pagamento, e todos os tipos de parto passaram a ser pagos de maneira igual. Após esta iniciativa, todos os seguros médicos privados também passaram a adotar a mesma polf́tica. Entretanto, não há nenhuma indicação de que esta mudança na política de pagamento do parto tenha provocado qualquer mudança na tendência de constante aumento na incidência de cesárea. Acontece que 
em condições de pagamento idêntico para todos os procedimentos, a cesárea continua compensando mais para o médico, considerando o ganho por hora. Enquanto uma cesárea não dura mais que uma hora, um parto normal poderá demorar de seis a doze vezes mais tempo.

Também não houve um efeito econômico, porque a cesariana continua sendo mais cara para o Inamps e para os seguros de saúde, visto que inclui o pagamento de assistentes e anestesistas, além de custos adicionais do hospital.

Outro fator importante é o uso da cesárea para a realização de laqueadura tubária. A esterilização cirúrgica não está formalmente proibida no Brasil, isto $\varepsilon$, não há nenhuma lei que a indique como crime. Contudo, existe uma ambigũidade sobre a questão que permitiu uma recente interpretação pelo Conselho $\mathrm{Fe}$ deral de Medicina, dizendo que sua realização, à exceção de circunstâncias excepcionais, ofende o Código Penal, uma vez que uma de suas cláusulas proscreve qualquer ato que cause "perda de órgão ou função", e que a laqueadura resulta em perda da função reprodutiva. Porém, outros juristas observam que os médicos, na atenção a seus pacientes e com o consentimento dos mesmos, realizam rotineiramente intervenções que resultam em perda de órgãos e funções, e que isto é considerado como um exercício legítimo da profissão. Uma esterilização cirúrgica, com o consentimento da mulher e a seu pedido geralmente contribui para o seu bem-estar biologico, psicológico e social e, assim, também estaria justíficada.

No entanto, esta ambigüidade $\varepsilon$ suficiente para que o Ministério da Saúde e o Inamps excluam a esterilizaçāo cirúrgica das alternativas aceitas para a regulação da fertilidade. Assim, o Ministério da Saúde não possui normas que possam ser aplicadas à prática da laqueadura tubária, e o Inamps nấo paga por esta cirurgia. Visto que o Inamps paga cerca de $75 \%$ de todos os serviços médicos, as pacientes e os médicos burlamno ao disfarçar a esterilização cirúrgica como qualquer outra cirurgia, desde um nódulo de mama até um cisto de ovário, mas geralmente como uma cesárea "normal".

A PNAD realizada pelo IBGE em 1986 inquiriu sobre a regulação da fertilidade (IBGE, 1986). Os dados coletados demonstraram que, em todo o país, três quartos de todas as laqueaduras tubárias foram realizadas por ocasião do último parto, variando de $61,25 \%$ em Sergipe até $85,9 \%$ no estado do Amazonas. $\mathrm{O}$ estado de São Paulo estava em segundo lugar, com 83\% (Berquó, 1988 - Tabela VI). O IBGE não perguntou se estes partos foram vaginais ou cesárea, mas o estudo de avaliação do PAISM, mencionado anterior- 
mente, constatou que em 1987, no estado de São Pau1o, $72 \%$ de todas as esterilizaçōes cirúrgicas entre as mulheres de baixa renda foram realizadas durante uma cesariana (Hardy e cols., 1988). Como outras formas de esterilizaçẫo pós-parto somente são realizadas em alguns poucos hospitais universitários, a porcentagem encontrada pela pesquisa do IBGE deve estar bem próxima de ser o total de laqueaduras realizadas durante uma cesariana.

\section{TABELA VI}

Prevalência de Esterilização Durante o Último Parto Entre Mulheres de 15-54 Anos, por Estado. Brasil, 1986.

\begin{tabular}{ll}
\hline Estado & $\%$ Esterilizadas \\
\hline & \\
Sergipe & 61,2 \\
Espfrito Santo & 62,8 \\
Alagoas & 64,4 \\
Minas Gerais & 65,5 \\
Santa Catarina & 68,6 \\
Bahia & 69,2 \\
Paraná & 69,4 \\
Rio Grande do Sul & 71,0 \\
Parafba & 73,0 \\
Goiás & 74,7 \\
Rio de Janeiro & 75,2 \\
Pernambuco & 75,6 \\
Distrito Federal & 75,6 \\
Maranhăo & 76,2 \\
Rio Grande do Norte & 76,3 \\
Mato Grosso do Sul & 77,0 \\
Piauf & 78,4 \\
Ceará & 78,8 \\
Mato Grosso do Norte & 79,2 \\
Pará & 82,6 \\
São Paulo & 83,0 \\
Amazonas & 85,9 \\
\hline Brasil & 74,7 \\
\hline
\end{tabular}

Fonte: IBGE, 1986

AS CONSEQÜÊNCIAS DA ALTA INCIDÊNCIA DE CESÅREAS

Os riscos da cesárea para o recém-nascido são de dois tipos. Um é o risco de interromper prematuraCadernos de Saăde Pứblica, RJ, 7 (2): 150-173, abr/jun, 1991 
mente a gravidez por erro de cálculo da idade gestacional, especialmente no caso de cesáreas com data marcada. Outro é o de angústia respiratória para os recém-nascidos de parto cesárea, em comparação com os de parto vaginal, mesmo que ambos estejam a termo.

Os dados disponfveis sugerem que o risco de prematuridade não é apenas uma hipótese, mas um risco real para a cesariana eletiva sem indicação médica. O estudo do PAISM realizado em 1988, em São Paulo, encontrou uma incidência $60 \%$ maior de prematuridade entre os bebês nascidos por cesárea com esterilização cirúrgica, em comparação com os nascidos por cesárea sem este procedimento, aceitando-se o fato de que a esterilização teria sido, em geral, a razāo para uma interrupção eletiva da gravidez (Tabela VII). Embora esta seja uma evidência indireta, é reforçada por dados de hospitais com altas taxas de cesáreas, a maioria delas eletiva, nos quais a taxa de prematuridade alcança $25 \%$ ou mais.

\section{TABELA VII}

Incidência de Prematuridade Entre Recém-nascidos por Cesárea, com e sem Laqueadura Simultânea. Estado de Sāo Paulo, 1988

\begin{tabular}{lccc}
\hline Tipo de & RN & Prematuros & Total Partos \\
Cesarea & $\mathrm{N}$ & $\%$ & Cesarea \\
\hline Com Laqueadura & 11 & 13,7 & 80 \\
Sem Laqueadura & 11 & 8,5 & 129 \\
\hline
\end{tabular}

Fonte: Hardy, 1988

A maior mortalidade e morbidade materna entre mulheres submetidas à cesárea é um achado comum em todos os estudos (Tabela VIII). Os dados brasileiros limitam-se às estatísticas de alguns hospitais, todos demonstrando um maior risco de morte para a cesárea do que para o parto vaginal (Faúndes e cols., 1985).

Uma das diferenças mais claras em morbidade está relacionada às infecções puerperais, que são muito mais freqüentes após cesárea do que parto vaginal. Esta é, também, uma das causas de mortalidade materna. Outra causa importante de morte durante a cesárea está relacionada à anestesia. Os acidentes e complicaçōes anestésicas e a aspiração de vômito são outros fatores que contribuem para um risco mais elevado de morte matema durante uma cesárea. Assim, uma intervenção criada para proteger a vida da mäe e da criança, quando indicada e realizada adequadamente, 
torna-se um perigo para um ou ambos, quando utilizada somente por conveniência do médico e da mãe, ou como resultado das incongruências do sistema de saúde.

\section{TABELA VIII}

Risco de Morte Materna de Acordo com o Tipo de Parto, Segundo Vários Autores

\begin{tabular}{lllccr}
\hline & & & \multicolumn{2}{c}{ Mortalidade } & Materna* \\
\cline { 5 - 5 } Autor & Perfodo & Local & Cesfrea & Vaginal & R.R. \\
\hline Rubin & $1975-76$ & Georgia & 10,5 & 0,97 & 10,8 \\
Petitti & 1979 & USA & 11,4 & 2,04 & 5,6 \\
Minkoll & 1977 & N.York & 10,8 & 1,70 & 6,3 \\
Evrard & $1965-75$ & Rhode Isl. & 6,9 & 0,27 & 25,7 \\
Frigolletto & $1968-78$ & Boston & 0,0 & 1,00 & - \\
Chevran-Breton & $1969-79$ & Rennes & 14,5 & 2,1 & 6,9 \\
Moldin & $1973-79$ & SuÉcia & 2,1 & 0,1 & 21,0 \\
Costa & 1979 & Recife & 68,3 & 1,9 & 35,9 \\
Fafindes & $1979-83$ & Campinas & 8,8 & 3,6 & 2,4 \\
\hline
\end{tabular}

Fonte: Falindes, 1985.

* Mortes maternas/10.000 partos

No entanto, há outras conseqūências da cesárea que são menos evidentes, e afetam a saúde da mãe e do bebê. Uma cesariana implica uma recuperação mais diffcil para a mãe, levando a um perfodo maior de separaçăo entre ela e o filho, uma demora no primeiro contato entre eles e no início da amamentação. Se acrescentarmos a isto um aumento no uso de analgésicos e o maior desconforto ao se lidar com o bebê, é fácil compreender porque a taxa e a duração da amamentação são afetadas pela cirurgia abdominal. Sabendo da importância do aleitamento materno para um país como o Brasil, este है um argumento forte contra a cesariana desnecessária (Barros e cols., 1986).

Nessa situação de condescendência com uma alta taxa de cesárea, de preferência das mulheres por esse tipo de parto e de conveniência para os médicos, elevase ainda mais o fndice para as mulheres que têm seu primeiro filho do que para as que já tiveram um parto vaginal. Este último grupo de mulheres terá um trabalho de parto mais rápído e mais fácil, o que representa menor inconveniência para os obstetras e uma menor chance de se intervir com uma cesárea.

Quando uma mulher fica com uma cicatriz uterina depois do primeiro bebê, seu futuro obstétrico já estấ comprometido. Primeiramente, para a maioria dos médicos, estabelece-se a necessidade absoluta de repetir o procedimento no próximo parto, sem esperar pela 
evolução normal do mesmo. A comprovação de que as provas de trabalho de parto resultam em parto vaginal para mais da metade das segundas gravidezes, sem maiores riscos para os bebês $\mathrm{e}$ as mâes, parece não impressionar os médicos brasileiros, como não impressiona os americanos. Estatísticas da Califómia indicam que em $98 \%$ dos nascimentos com uma cesárea anterior repete-se este procedimento (Petitti e cols., 1982). Mesmo com falta de dados precisos, não há dúvida que o mesmo ocorre no Brasil. Há raras exceções de alguns hospitais, em ambos os países, que mostram um alto índice de parto vaginal após uma prova de trabalho de parto (Faúndes e cols., 1988).

A cicatriz uterina pode ter menos influência sobre a evolução do parto do que inicialmente se pensava, porém aumenta o risco de algumas sérias complicaçỏes como placenta prévia, outras patologias hemorrágicas, morbidade neonatal e infecçốes puerperais (Faúndes, 1983 e Díaz Moraguez e cols., 1981 - Tabela IX).

\section{TABELA IX}

Porcentagem de Casos com Complicaçōes de Parto, Puerpério e do Recém-nascido, Segundo Antecedente

Hístória de Cesárea. Mães com Apenas um Parto Anterior

\begin{tabular}{|c|c|c|c|c|}
\hline \multirow[b]{2}{*}{ Complicaçס̄es } & \multicolumn{3}{|c|}{ A nt. Cesárea } & \multirow[b]{2}{*}{$N$} \\
\hline & 0 & 1 & $P$ & \\
\hline Placenta PrÉvia & 0,3 & 1,2 & 0,0001 & 8.090 \\
\hline \multicolumn{5}{|l|}{ Outras Complicaçōes Hemor. do } \\
\hline Fim da Gravidez e Parto & 0,2 & 0,9 & 0,0001 & 8.111 \\
\hline Ruptura Premat, de Membranas & 9,0 & 11,5 & 0,05 & 7.808 \\
\hline Mecónio & 8,7 & 25,0 & 0,0001 & 7.613 \\
\hline Infecçăo Puerperal & 7,4 & 17,6 & 0,0001 & 8.129 \\
\hline APGAR $0-6$ & 5,3 & 8,5 & 0,0001 & 7.988 \\
\hline Peso Reckm-nascido $<2500 \mathrm{~g}$ & 8,3 & 10,1 & N.S. & 8.151 \\
\hline Morbidade Neonatal & 10,7 & 13,4 & 0,036 & 7.838 \\
\hline Mortalidade Perinatal & 2,4 & 3,1 & N.S. & 8.123 \\
\hline
\end{tabular}

Fonte: Fafindes, 1983.

Um efeito final da alta prevalência de cesáreas $\varepsilon$ a limitação da fecundidade entre a população envolvida. Como explicado anteriormente, em situaçöes de baixa incidência de cesáreas, a taxa é semelhante ou menor para o primeiro parto, mas com o aumento da incidência, sobe a taxa de cesáreas entre as nulíparas (Petitti e cols., 1979 - Tabela X). Em circunstâncias de taxas excepcionalmente altas, como no Brasil, e sobretudo quando somente os casos rápidos e fáceis evoluem para parto vaginal, a incidência entre as nulfCadernos de Sǻde Páblica, RJ, 7 (2): 150-173, abr/jun, 1991 
paras deve ser ainda mais alta. Quando a prática geral ¿ "depois de uma cesárea, sempre cesárea", e a esterilização cirúrgica praticada sistematicamente após a terceira cesárea, todas essas mulheres terāo no máximo três nascidos vivos (Faúndes, 1986). Três pode ser o número ideal de filhos para muitos casais, mas é improvável que todos estejam satisfeitos com essa situação, particularmente considerando que a cicatriz uterina aumenta o risco de morbidade neonatal e, conseqüentemente, os óbitos infantis. Deve-se recordar que isso não é o resultado de uma decisão planejada, mas uma consequeência involuntária da maneira como o primeiro parto foi tratado.

\section{TABELA X}

Incidência de Cesárea no Primeiro Parto e em Todas as Paridades. Califómia, 1960 - 1975

\begin{tabular}{lccc}
\hline & \multicolumn{3}{c}{ Incidencia de Cesłrea } \\
\cline { 2 - 4 } Ano & Total & Prim.Parto & Dif. (\%) \\
\hline 1960 & 4,87 & 4,83 & $-0,8$ \\
1965 & 4,97 & 5,08 & 2,2 \\
1970 & 6,85 & 7,2 & 6,3 \\
1975 & 12,76 & 14,60 & 14,4 \\
\hline
\end{tabular}

Fonte: Petitti, 1982.

\section{CONSEQÜENCIAS, ECONÔMICAS DOS ALTOS INDICES DE CESÁREAS}

Para o médico, a decisão de realizar uma cesárea eletiva, ao invés de um parto vaginal, pode parecer não ter nenhuma conseqưência econômica. Contudo, a soma de muitas decisões semelhantes tomadas diariamente pode afetar seriamente o custo da assistencia à saúde materno-infantil de diversas maneiras.

O custo mais fácil de se identificar é aquele resultante da cirurgia comparado ao do parto vaginal assistido, somado a uma estadia mais prolongada e ao maior uso de medicamentos e outros materiais de consumo. No Hospital da Unicamp, a estimativa da diferença de custo entre os dois tipos de parto foi de cerca de $50 \%$ maior para a cesárea (US $\$ 48.00$ para o parto normal e US $\$ 96.00$ para a cesárea).

Outro mecanismo que aumenta o custo da assistência à saúde é o derivado da prematuridade iatrogê- 
nica. Um bebê prematuro requer uma assistência neonatal intensiva por algum tempo, um cuidado semi-intensivo anda mais longo, e aumentará a demanda dos serviços de saúde, pelo menos durante a primeira infância. Conseguimos estimar o custo médio da assistência ao recém-nascido prematuro apenas durante o cuidado intensivo, pois as variações no custo posterior são muito grandes e dificeis de calcular. Esse custo, em nosso hospital, foi de US $\$ 1.050$, baseado no custo diário de US\$150 e em uma permanência média de sete dias.

Para calcular o custo excedente de cesáreas desnecessárias, estimamos a taxa que seria justificada por razōes médicas em $15 \%$ e, então, calculamos o custo de cada aumento de $1 \%$ acima dessa taxa. Estimando-se que há 4 milhões de nascimentos por ano no Brasil, $1 \%$ representa 40 mil cesáreas. $O$ custo excedente da assistência à mãe hospitalizada para essas 40 mil cesáreas seria de US $\$ 1.920 .000$ (US $\$ 48 \mathrm{x}$ 40.000).

Para estimar o custo da prematuridade iatrogênica, usamos a diferença de $5,2 \%$ entre cesáreas presumivelmente justificadas e injustificadas, encontrada na avaliação do PAISM, no estado de São Paulo (Tabela VII). Dentro desse conceito, cada aumento de $1 \%$ na taxa, ou cada 40 mil cesáreas adicionais, resultará em 2.080 recém-nascidos iatrogenicamente prematuros, a um custo de US $\$ 2.184 .000$ (US $\$ 1.050 \mathrm{x}$ 2.080).

Considerando somente $o$ custo aumentado da assistência às mães e da assistência intensiva aos prematuros, cada aumento de $1 \%$ nas cesáreas custará US\$ 4.104.000. Se fosse mantida a taxa de $31 \%$ de 1980 , - excedente de cesáreas desnecessárias seria de $16 \%$ (31\% menos $15 \%$ das justificadas) e o seu custo para a nação poderia ser estimado em US $\$ 65.664 .000$. Se a taxa tivesse aumentado para $40 \%$, conforme projeções a partir dos dados do Inamps, o excedente de cesáreas desnecessárias seria 25\% (40\% menos $15 \%$ das justificadas), ou seja, 1 milhão de intervençōes. Se este fosse o caso, em 1989, o custo total da iatrogenia médica desnecessária seria de US $\$ 102.600 .000$. Cerca de $80 \%$ deste dinheiro vêm de fundos públicos, como os governos federal, estaduais e municipais.

Este desperdício de recursos já escassos é condenável, dada as deficiências em assistência pré-natal básica, os baixos índices de diagnósticos preventivos através do esfregaço de Papanicolaou e as deficiências em várias outras necessidades básicas de saúde.

Essas estimativas, porém, devem ser consideradas apenas como uma aproximaçẵo. Existem fatores que podem alterar os numeros finais de maneira oposta. $O$ custo atual do cuidado intensivo a prematuros foi 
superestimado porque, no momento, os hospitais brasileiros nâo possuem recursos para prover tal assistência a $100 \%$ dos recém-nascidos antes do termo. Por outro lado, como não inclui todos os outros custos para os serviços de saúde resultantes do aumento da demanda para a assistência desses recém-nascidos, o custo É obviamente subestimado. Também nāo inclui o custo da taxa e duração reduzidas do aleitamento matemo, com todos os conhecidos efeitos sobre a morbidade infantil e a demanda pelos serviços.

\section{AÇÕES E MUDANÇAS NECESSÁRIAS PARA}

REVERTER A TENDENCIA DE AUMENTO DA TAXA DE CESÁREAS

A análise pregressa das principais causas do aumento nos índices de cesárea no Brasil pode ser usada para orientar a formulação de políticas para reverter essa tendência. A seguir, tentaremos manter a mesma ordem, combinando os problemas com as possíveis soluçōes.

\section{Intervenções sócio-cult urais}

Basicamente, o que se observa é que a cesárea é uma moda no Brasil. Como mudar essa moda para outra que valorize o parto natural, é uma questão que requer a ajuda de especialistas em comunicação. Podemos dizer que a mensagem deveria incluir alguns pontos fundamentais.

Primeiramente, a mensagem deveria deixar claro que uma cesárea não significa, necessariamente, $\mathrm{a}$ ausência de dor e que o parto vaginal pode ocorrer com pouca ou nenhuma dor. A alegria do parto vaginal deveria ser exaltada, assim como o valor emocional e físico do contato imediato entre mãe e recém-nascido, o qual não é possível com uma cesárea. Deve-se tomar cuidado para não culpar as mulheres que não conseguirem ter um parto normal, mas o esforço e a intenção para isso devem ser louvados.

Outra mensagem importante é que o prazer sexual independe do tipo de parto. Especialistas e educadores em sexologia devem enfatizar esse aspecto em suas conferências, cursos, artigos de jornais e revistas, assim como também durante sua participaçảo em congressos de ginecologia e obstetrícia.

O terceiro aspecto, a maior segurança para a mãe e para o recém-nascido num parto normal, e os perigos para ambos numa cesárea escolhida somente por conveniência e com data marcada, é mais difícil de ser tratado.

Os obstetras mais conhecidos e de maior prestígio são, também, os que têm a clientela mais numerosa e mais rica. Conseqũentemente, a sua prática exige 
a aceitação da cesárea eletiva com data marcada, a fim de poder atender à demanda. Esses obstetras são alnda os oradores em congressos e cursos e escrevem em publicações médicas e leigas. Por esses papéis sociais que assumem, têm de acreditar que o que fazem é o correto, e estấo sinceramente convencidos disso. O processo de mudança dessa convicção não será fácil. A demonstração dos resultados de estudos estrangeiros não é suficiente, mas a coleta cuidadosa de dados brasileiros sobre as várias consequêencias da cesárea será um requisito fundamental, se quisermos superar este quadro atual.

Mudanças na organização da assistência obstétrica

Essa é uma das questões mais dificeis, e ainda não visualizamos uma saída para o caos atual se a assistência obstétrica continuar a ser vista de maneira totalmente individualizada. A natureza do processo de estar grávida e dar à luz é muito emocional e pessoal, e a confiança na pessoa que cuida desse processo tem um imenso valor psicológico. Contudo, nảo há nada contra a transferência dessa confiança de um individuo para uma equipe.

A equipe pode ser formada por apenas duas ou três pessoas ou pode ser um grupo maior. $\mathrm{Na}$ prática privada e do seguro social, a equipe pode ser um médico e uma enfermeira obstétrica ou parteira, ou um obstetra mais experiente com alguns assistentes e parteiras. Psicólogos, fisioterapeutas, educadores em saúde e outros profissionais também podem participar do grupo de trabalho durante o preparo pre-natal para o parto e a maternidade.

A conveniência para o obstetra e para a māe de uma equipe para a assistência à gravidez e ao parto não é fácil de se transmitir. Os médicos têm medo de perder as pacientes e as mães de perder o atendimento personalizado. Convencer ambos de que têm mais a ganhar do que a perder não é tarefa fácil no Brasil.

Um pré-requisito muito importante é o resgate da função da parteira (obstetriz) como uma estreita colaboradora do obstetra, assim como é a enfermeira para o cirurgião ou para o médico de UTI. A parteira já não constitui mais uma profissão no Brasil e o processo desse resgate não será fácil. O processo deveria ser bem planejado a nfvel central e em alguns estados - chave. Deveria ser iniciado o mais cedo possível, pois levará alguns anos até começar a mostrar resultados.

A escassez de profissionais de saúde, que não médicos, é muito grande, e será fácil justificar esta iniciativa para aumentar o número desses profissionais. 
Contudo, a oposição será grande, e a situaçāo deverá ser cuidadosamente avaliada para se estabelecer estratégias adequadas para vencer essa resistência, tanto por parte de enfermeiras como de obstetras.

Finalmente, há a questão do treinamento adequado dos médicos para a assistência ao parto normal. Novamente é um problema diffcil, que envolve o ensino da medicina a nível da graduação e residência médica. Muitos são os problemas que interferem no treinamento obstétrico adequado e que deverão ser superados.

Já foram discutidas anteriormente a conveniência da cesárea para os médicos e a falta de atrativo pela alternativa do parto vaginal. Há pouca motivação para se aprender como acompanhar o trabalho de parto e para entender as grandes variaçōes da normalidade. Muitas das ações sugeridas acima deveriam ajudar na solução desse problema.

Um segundo aspecto é que obstetrícia aprende-se através da prática, e o treinamento atual depara-se com dois obstáculos à prática da assistência ao parto normal. Há cada vez menos partos vaginais para o aprendizado e os obstetras com maior experiência estão mais raramente disponíveis para ensinar. A partir dessa descrição, não é difícil imaginar a gigantesca tarefa envolvida na melhora do treinamento. Novamente, porêm, é uma tarefa que requer planejamento básico, uma boa estratégia para implementação e uma forte polftica de execução.

\section{Ações institucionais e legais}

Essa é a área mais estimulante, pois oferece melhores possibilidades de provocar alterações nos fndices de cesárea. O fato de que mais de três quartos dos partos são pagos pelos cofres públicos cria condiçōes que permitem que a taxa de cesárea seja influenciada por uma interaçåo de estímulos e de algumas formas aceitáveis de coerção.

As instituições de saúde pagas pelo Inamps são credenciadas por preencherem alguns requisitos mínimos de qualidade. O Inamps tem o direito de fazer auditorias nas atividades desses hospitais. Apesar destas auditorias serem normalmente apenas financeiras, também poderiam incluir aspectos técnicos. A taxa de cesárea de cada hospital poderia ser usada como um indicador de qualidade de assistência obstétrica, e assim poderia ser estabelecido um limite nesta taxa como condição para a manutenção do credenciamento desses serviços.

Como os indices de cesárea variam enormemente por regiöes, o limite inicial poderia variar dessa maneira, utilizando-se, por exemplo, a média regional atual. 
Qualquer Índice acima deste limite poderia exigir uma explicação detalhada do diretor clínico do hospital. Qualquer hospital com dois meses sucessivos de índices acima do limite seria objeto de uma auditoria de alto nível técnico para examinar, caso a caso, as in dicações das cesáreas e os resultados matemo-fetais. Como resultado dessa auditoria, seriam feitas recomendaçōes ao diretor clínico de medidas para evitar cesarianas desnecessárias. Se depois disso, a taxa de cesárea daquele hospital continuasse acima do limite, restariam pelo menos duas alternativas. Uma seria a suspensão do credenciamento para a assistência obstétrica do hospital e a outra seria o pagamento dos partos somente até o limite estabelecido, não sendo aceitas cobranças para cesáreas além desse índice.

Tais medidas merecem considerações de aspecto prático e legal, incluindo a seleção cuidadosa dos grupos de alto nf́vel técnico responsável pelas auditorias. Esses grupos deveriam incluir um representante do Conselho Regional de Medicina (CRM), ou -0 presidente da Comissão de Ética do hospital (que representa o CRM).

Outra decisão polftica importante que o Inamps deveria adotar é a autorização do pagamento da analgesia peridural para o parto em mulheres nulíparas. Isso mudará não somente a motivação das mulheres que atualmente escolhem uma cesárea para evitar a dor, mas também significará um lucro financeiro para o Inamps. Atualmente o Inamps paga não somente 0 obstetra e $o$ anestesista que participam da intervenção, mas também pelo menos um assistente e outros custos adicionais, enquanto que para o parto normal de uma nulípara pagaria somente os dois primeiros médicos. Além disso, enquanto uma mulher com uma primeira cesárea terá uma segunda na próxima gravidez, as mulheres cujo primeiro parto foi normal terão maior chance de parto normal no futuro.

Uma decisão mais diffcil, porém necessária, refere-se à esterilização cirúrgica e à anticoncepção pós-parto. Esse item requer dois níveis diferentes de análise e decisảo política. Primeiramente, há o problema de falta de opçōes anticoncepcionais reais para a muIher segurada pelo Inamps. Os hospitais que oferecem anticoncepção pós-parto (outra que não cesárea/esterilização) são a absoluta exceção no Brasil de hoje, assim como também as unidades básicas de saúde que oferecem serviços anticoncepcionais. Não há dúvida de que a demanda por cesáreas como forma de se obter uma laqueadura tubária será muito reduzida se as mulheres tiverem fácil e real acesso às alternativas efetivas e aceitáveis de anticoncepção. Apesar do Inamps oferecer teoricamente tais serviços, a implementação explícita dessa política é quase inexistente. 
Um exame das razões para esse fracasso e a adoção de medidas corretivas necessárias contribuirão para a redução da demanda pela cesárea/laqueadura.

O outro nível de discussão refere-se à visão distorcida das mulheres e médicos que acreditam ser necessária uma cesárea para justificar uma laqueadura tubária. Muitas mulheres póbres que ja têm o número desejado de filhos engravidam novamente para ter acesso a uma esterilizaçāo cirúrgica realizada juntamente com a cesárea, ilustrando as perversōes absurdas e perigosas que o sistema de atenção à saúde no Brasil criou. A política de mudança mais simples que poderá solucionar esse problema é o pagamento das esterilizaçōes cirúrgicas, da mesma maneira como para quaisquer outros serviços médicos. Para que isso seja possível, - Inamps deveria obter de seu departamento jurídico uma declaração de que não há impedimento legal para a laqueadura tubária (e vasectomia), dentro de certos limites e cumprindo um mínimo de exigências. Existem, porém, implicaçôes políticas que envolvem uma tal decisão, que têm sido vistas como obstáculos para as mudanças propostas. É sabido, porém, que o momento polf́tico hoje é bastante favorável a essa mudança, desde que as estratégias apropriadas sejam adotadas, como será discutido mais tarde.

\section{Mudanças em práticas obstétricas}

Apesar de haver alguma justaposição dos assuntos discutidos acima, ações também podem ser tomadas para mudar algumas práticas obstétricas quase rotineiras no Brasil, em relação à indicação de cesárea.

Além das cesáreas a pedido das pacientes, existem quatro indicaçôes obstétricas freqüentes: sofrimento fetal, desproporçấo céfalo-pélvica, apresentação pélvica e história prévia de cesárea.

Em relação ao sofrimento fetal, a monitorização eletrônica ainda não é amplamente utilizada no Brasil, para que tenha um impacto significativo na indicação da cesárea, como parece ser o caso nos EUA e outros pafses desenvolvidos (Prentice e Lind, 1987). A ausência de dados nacionais concretos impede qualquer recomendação a esse respeito.

A desproporçâo céfalo-pélvịca é a indicação mais freqüente em muitos hospitais. E utilizada sempre que o trabalho de parto não progride de acordo com as expectativas do obstetra, sem levar em conta outras disfunções que possam ser a causa da demora. Não raramente, também pode ser o resultado de um desconhecimento da grande variabilidade na evolução do trabalho de parto. As principais açōes que podem ajudar a reduzir essa indicação são o uso do partograma

Cadernos de Satade Páblica, RJ, 7 (2): 150-173, abr/jun, 1991 
e a adoção de uma atitude mais ativa na correção das disfunções, quando a evolução do parto é demorada ou arrastada. $O$ uso correto de analgesia, ocitocina e rotura artificial das membranas, na ocasiẩo oportuna e na paciente certa, reduzirão significativamente a necessidade de intervençōes cirúrgicas. Essa recomendação está intimamente relacionada com o treinamento, discutido anteriormente.

O uso mais liberal de cesarianas em casos de apresentaçăo pélvica tem sido responsável por uma grande parcela de aumento na taxa de cesáreas nos EUA. Os melhores resultados perinatais parecem justificar essa conduta em muitos casos, mas não em todos, como é atualmente o caso no Brasil. Uma seleção mais cuidadosa das pacientes, permitindo a evolução vaginal do parto naquelas que näo apresentem alto risco para esta via, evitará um certo número de intervençōes. Essa É, talvez, a recomendação mais diff́cil, pois exige um diagnóstico preciso da variedade da apresentação pélvica, do tamanho da pelve materna e do feto, e do grau de flexão da cabeça fetal. Também exige a presença de um obstetra com alguma experiência no atendimento de partos pélvicos, que não $\varepsilon$ facilmente encontrado na assistência obstétrica atual.

Além disso, desde que a apresentação pélvica ocorre apenas em aproximadamente $2 \%$ de todos os casos, uma mudança na incidência de cesáreas nesse grupo em particular não será significativa, dadas as proporçōes epidêmicas do problema no Brasil hoje.

Uma indicação mais freqüente e em rápida ascensão é a de história de cesariana prévia. O sucesso de um parto vaginal e a ausência de um maior risco com o acompanhamento do trabalho de parto nestes casos têm sido repetidamente registrados na literatura obstétrica brasileira e internacional, independentemente da causa que determinou a cesárea anterior (Tabela $\mathrm{XI}$ ).

\section{TABELA XI}

Incidência de Partos Cesáreas de Acordo com o Número de Cesáreas Anteriores em Dois Perfodos, Unicamp

\begin{tabular}{crccccc}
\hline \multirow{2}{*}{$\begin{array}{c}\text { Námero de } \\
\text { Cesárea }\end{array}$} & \multicolumn{2}{c}{$1977-1980$} & & $1986-1987$ & \\
\cline { 2 - 3 } & Total & \% Cesarea & & Total & \%Cesarea & P \\
\hline 0 & 2.268 & 18,7 & & 1.019 & 18,9 & NS \\
1 & 254 & 57,0 & & 132 & 47,0 & 0,06 \\
2 ou mais & 110 & 96,4 & & 101 & 97,0 & NS \\
\hline
\end{tabular}

Fonte: Falndes, 1988. 
Dado que a história de uma cesárea prévia determina atualmente sua repetição em quase todos os casos no Brasil, a introdução de uma rotina de acompanhamento do trabalho de parto para essas mulheres pode reduzir pela metade o fndice de cesáreas por esta indicação. Isso requer' a definição de critérios objetivos na triagem e acompanhamento adequado do processo do trabalho de parto (Faúndes e cols., 1988). Novamente o uso do partograma pode se mostrar útil, assim como a melhoria do treinamento daqueles que se ocupam da assistência a essas pacientes.

Finalmente, mudanças na assistência pre-natal podem, também, ter um impacto na taxa de cesáreas, preparando a mäe para o trabalho e o parto, tanto física como psicologicamente. Esse aspecto está intimamente relacionado ao resgate da profissão da partei$\mathrm{ra}$, ao treinamento dos médicos e outros profissionais de saúde e à substituição da assistência individual por uma de equipe.

Estratégias para a implementação de ações e de mudanças de políticas

A implementação de açōes e de mudanças de polfticas aqui propostas requerem um forte apoio social, que pode ser obtido através de informaçáo adequada ao páblico, com a colaboração da imprensa (escrita, rádío e TV). Também requerem uma avaliação contínua e restrita para a introdução das correçōes necessárias.

A estratégia para o desenvolvimento e implantação de políticas e açōes deveria ser cuidadosamente elaborada, de forma a contar com o máximo de aliados e o mínimo de oponentes possível, evitando erros que possam transformar um aliado em potencial em opositor. Há o precedente da iniciativa da Comissáo da Perinatologia do Ministério da Saúde. Ela decidiu iniciar uma campanha nacional contra as altas taxas de cesáreas, porém a maneira como a decisão foi tomada e apresentada ao público causou o embaraço e irritação desnecessários da Federação Brasileira das Sociedades de Ginecologia e Obstetrícia (Febrasgo). Com a oposição da Febrasgo, a campanha perdeu seu impacto e teve muito pouca influência sobre a prática das cirurgias cesarianas.

Grupos como a Febrasgo, o Conselho Federal de Medicina e os CRM dos estados, a Associação Médica Bjasileira e outros similares deveriam ser informados e sua colaboração formalmente solicitada. Outros contribuidores muito importantes seriam todos os grupos de mulheres, que se estão tomando cada vez mais fortes, maiores e melhor organizados. 
Porém, a condição fundamental para se ter sucesso na reversão da atual tendência da taxa de cesáreas É uma liderança política forte e bem informada, com uma visão clara do problema e suas soluçōes e, sobretudo, com vontade de realizar as mudanças necessárias.

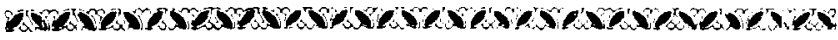

The authors analyse the current cesarean section situation in Brazil. In the last decade it has reached extremely high levels of incidence, higher than any other country. Social-economic and regional differences are established through the available national data on the cesarean section incidence. There is a higher incidence on wealthier regions and women. The factors influencing this high incidence, including socio-cultural, obstetric care organization, legal and institutional ones are also considered. Special attention is given to the problem of female surgical sterilization which is forbidden in the country and is performed through inadequate indication of a cesarean section. Consequences for maternal and perinatal morbidity and mortality, the effects on population fertility and extra public expenses are considered. Interventions and attitude changes are proposed at several levels to reverse this increasing tendency of cesarean section incidence in the country.

\section{REFERÊNCIAS BIBLIOGRÁFICAS}

BARROS, F. C., VAUGHAM, J. P., VICTORA, C.G. "Why so many cesarean sections. The need for further policy change in Brazil". Health Policy Plan. 1:19, 1986.

BERQU $6, \mathrm{E}$. "Contraception in Brazil today". XII World Congress of Gynecology and Obstetrics, Rio de Janeiro, Brasil, 1988.

FAUNDES, A. "Cesection scarring: risk to future reproduction". $X$ Congress of Gynecology and Obstetrics, San Francisco, USA, 1983.

FAÚNDES, A. "As cesáreas e as modificaçōes nos nfveis de fecundidade". População e Salde. Vol. I pp 73-91. Editora Unicamp, Campinas, 1986.

FAUNDES, A., HERMANN, V., CECATTI, J. G. "Análise da mortalidade materna em partos cesfreos no municfpio de Campinas, 1979-1983". Femina 13:516, 1985.

FAÚNDES, A., AMARAL, E., PINTO E ŚILVA, J. L., GAMA DA SILVA, J. C., PINOTTI, J. A. "Trabalho de parto em pacientes com antecedentes de cicatriz de cesárea". Gin. Obstet. Bras. 11:103, 1988.

GOYERT, L., BOTTOMS, S. F., TREADWELL, M, C., NEHRA, P. C. "The physician factor in cesarean birth rates". N. Engl. J. Med. 320:706, 1989. 
GRANADO-NEIVA, J. G. “Operaçăo cesárea no Instituto Nacional de Assistência Médica da Previdéncia Social". XXVI Jornada. Brasileira de Ginecologia e Obstetricia, Rio de Janeiro, 1982.

HARDY, E, et al. "Avaliação do Programa de Assistência Integral a Saúde da Mulher no Estado de São Paulo. Resultados da área metropolitana e do interior do estado. Informaçóes relativas ao prénatal, parto e revisắo pós-parto". Centro de Pesquisas e Controle das Doenças Materno-Infantis de Campinas (Cemicamp), 1988.

INSTITUTO BRA SILEIRO DE GEOGRAFIA E ESTATISTICA. Pesquisa Nacional por Amostra de Domictlios (PNAD), 1982.

INSTITUTO BRASILEIRO DE GEOGRAFIA E ESTATISTICA. Pesquisa Nacional por Amostra de Domictilios (PNAD), 1986.

JANOWITZ, B. "Cesarean section in Brazil". Soc. Scie. \& Med. $16: 19,1982$.

JANOWITZ, B. "Cesarean delivery in the Northeast Region of Brazil". Am. J. Publ. Health 75:560, 1985.

MELLO, C. G. "Privatizaçăo e produtividade dos serviços de saáde. Pesquisa setorial sobre incidencia da cesfrea". Revista Paulista de Hospitais 17:3, 1969.

MORAGUEZ, A. J. D., PINTO E SILVA, J. L., PINOTTI, J. A. FAUNDES, A. "Prognóstico obstétrico e perinatal da mulher portadora de cicatriz de operação cesareana". Gin. Obstet. Bras. 4:173, 1981.

PETITTI, D. B., CEFALO, R. C., SHAPTO, S., WHALLEY, P. "In-hospital maternal mortality in the United States: time trends and relation to method of delivery". Obstet. Gynecol. $59: 6,1982$.

PETITTI, D. B., OLSON, R. D., WILLIAMS, R. L. "C-Sections in California: 1960-1975". Am. J. Obstet. Gynecol. 133:391, 1979.

PRENTICE, A., LIND, T. "Fetal heart rate monitoring during labour - too frequent intervention, too little benefit". Lancet, Dec 12, 1987. pP 1375-7.

ROCHA, J. S. Y., ORTIZ, P. C., FUNG, Y. T. “A incidencia da cesárea e a remuneraçăo da assistếncia ao parto". Rev. Paulista de Medicina 104:167, 1986.

UNIVERSIDADE ESTADUAL DE CAMPINAS. "Cesariana: incidencia, fatores que a determinam e conseqūéncias maternas e perinatais". Relatório do Simpósio. Campinas, Brasil, 1982. 